\title{
Social determinants of health-Street children at crossroads
}

\author{
Anjali Gupta ${ }^{1,2}$ \\ ${ }^{1}$ Research Scholar, Community Social Medicine, Jawaharlal Nehru University, New Delhi, India \\ ${ }^{2}$ Sr. Programme Officer, Voluntary Health Association of India, New Delhi, India; \\ anjali.garg1@yahoo.com, anjali_g1@rediffmail.com
}

Received 29 May 2012; revised 27 June 2012; accepted 6 July 2012

\section{ABSTRACT}

This paper discusses the findings of a research project which is an exploratory cum descriptive study [1] that aims to describe and examine the state and nature of the quality of life of street children accommodated at an unorganised colony in the city of Delhi. It provides a social profile of children and their families, and exploring the needs and aspirations of these children living in especially difficult circumstances. A non-probability sample of 100 street children in the age group of 5 - 16 years was randomly selected guided by their availability. An interview schedule was constructed and administered to gather data. The statistical analyses comprised frequencies and percentages on all the sections of the interview schedule. Thematic content analysis was used to analyse data from openended questions and observations. Case studies were supportive in giving an insight into the lives of children living in especially difficult circumstances. Findings suggest that the quality of life of the participants in this study was depressed due to a lack of access or substandard educational and medical facilities, or absence of emotional support from their poverty stricken families. The existing limited programmes by the government or the civil society for the welfare of street children are lacking in their focus and do not include the voices and needs of the beneficiaries. Although service providers expressed sympathy for street children, many regarded them as deviants, delinquents, future criminals, and a public nuisance. Based on the findings, it has been suggested that the street child phenomenon necessitates a partnership between governmental and non-governmental organizations to provide for policy and legislation, funding and resources to translate pro- grams into concrete plans of action. It has further been argued that such an approach should extend to children using their resourcefulness and creativity, and show that they can be significant in development interventions. Children illustrate both the need for participatory approaches and the problems that arise when perceptions of participants conflict with those of experts.

Keywords: Street Children; Definition; Resourcefulness; Health

\section{INTRODUCTION}

With a population of more than 1 billion in 2000, India has the largest population of the street children ${ }^{1}$ in the world. A distressing phenomenon of the growth of the Indian population is that every year nearly 21 million children are born in India of whom eight million die due to various infections and diseases. This means that every year nearly 13 million children are added to the child population. India accounts for over $20 \%$ of children's deaths worldwide from preventable diseases, a number much larger than any other country. Around 28 percent of the deaths are linked to poor sanitation and unsafe drinking water. This toll is also compounded by malnutrition (The Economist, New Delhi, 20 October, 2009). Even by conservative measures statistics reveal that 80 lakh children in India are presently in out of school category. This figure includes 1.3 lakh children just in New Delhi (Times of India, New Delhi, 13 September 2009). The crucial question is "What are these 80 lakh children doing if not going to school?" They could either be sitting idle or loitering around on the streets or engaged in some work. If these children belong to families in distress, they have to earn to support their families. If they are without families and are a part of children living

${ }^{1}$ The term "street children" has been used inter changeably with "children in especially difficult circumstances” in the remaining document. 
on the street, then again they have to earn in order to survive. These children are generally in the category of "nowhere children" and in all probability most of them are working.

Majority of these children live and work in the cities of urban India. They are generally found in slum settlements, on railway stations, beneath flyovers, around temples and busy markets. They spend most of their time on the streets. A significant proportion of these children are working in the unorganized or informal sector in every city, big or small, offering cheap labour and catering to the various needs of the city dwellers. They suffer from various kinds of deprivation and denial of basic rights and necessities like education, health, food, shelter, physical and emotional security and recreation. Children on the streets are prone to various health hazards, the most common being under nutrition and malnutrition, anaemia, skin and other infections. They are also susceptible to drug/alcohol addiction, and to inhalants such as nail polish, rubber, which offer them an escape from reality and hunger.

This paper presents the findings of an exploratory research study of the street children in Sangam Vihar, one of the biggest unauthorised colonies of South Delhi [1]. It analysed their situation and supported the belief that the problem of street children is deep rooted and has multiple dimensions. This research work focuses on street children for three reasons. Firstly if they can be taken care of, it will prevent the emergence of children in need of care and care and protection and those in conflict with law to some extent. Secondly neglect of the youngest and the most vulnerable population is something that must be addressed urgently. And lastly for a practical reason, interaction and work is more feasible with this category of children than the institutionalized street children.

Section 2 of the paper reviews the literature and centres on the magnitude of street children in the country. It sets the context of the study in focus and presents an overview comprising of a brief analysis of their health condition; access to basic services; psychological health and; vulnerabilities and exploitation. The review also attempts to cover available information and research on the major characteristics and different aspects of conditions of street children in varied urban settings.

Section 3 elaborates the Methodology of the study. It details the purpose, the design and the research tools used to achieve the objectives. This being an exploratory study, it is descriptive to the extent that it is presenting observed facts and figures regarding the street children and provides a full picture of their social dynamics. The respondents comprise of children in especially difficult circumstances in Sangam Vihar, one of the biggest unauthorized colonies in South Delhi. Problems and limita- tions encountered during the course of study have also been put together at the end of this section. These few notable limitations to the study however do not hinder the main objectives of the study.

The fourth section focuses on the socio-economic backgrounds of the selected children. Keeping in context the critical influence, of the family as well as the peer group, school, work environment and the community around them, on the development of a child, this section examines in detail their background and most importantly it attempts to study the perceptions of the children about the institutional services. It sheds light on the factors that forced these children to leave their families and dwell on the streets. It also analyses the status and levels of education, health, habits, emotional insecurity and hopes of institutionalized children. The narratives and case reports of some of these children bring forth their real life experiences which also put a big question mark on the state of government efforts, to bring a substantial decline in the number of street children and level of implementation of the existing policies and programmes towards providing these children better facilities for their overall growth and development.

The fifth section focuses on the utilization of the health care delivery system and the health status of the street children. The final or the sixth section presents an analysis of the findings in the light of which it addresses some of the current policy debates about the definition of street children or the need of government to collaborate with the local and credible non governmental organizations for a better reach and effective implementation of their programmes, based on the needs of the beneficiaries.

\section{CONCEPTUAL FRAMEWORK- A BRIEF LITERATURE REVIEW}

The most frequently assessed social determinant in child health research is socioeconomic status since health is a dynamic concept embracing biological and social dimensions of the well being of man [2]. The physical, psychological and social and economic context that we live in cannot be ignored and in fact have to form the basis of our understanding of health. Besides health services there are many other significant factors that influence the health of a population, such as social and economic factors like nutrition, water supply, environmental sanitation, housing, education, income and its distribution, communication, transport and social structure [3].

Poor housing, sanitation, malnutrition, exposure to infections, high environmental risks, exposure to vagaries of weather, lack of parental guidance and supervision and early childhood labor are endemic and contribute to ill 
health of younger children. The circumstances in which street children live seriously jeopardize their health, safety and moral health [4].

Several studies have shown that apart from physical and sexual exploitation, undernourishment, poor health conditions and a high prevalence of diseases and infections are features common in the lives of street children. Because of the vulnerable and precarious situations in which they live, the incidence among them of under nutrition and other health problems seems particularly high. Poor, inadequate shelter arrangements adopted by homeless street children, inadequate and poor quality diets, at times starvation, lack of access to medical facilities, respiratory infections, skin ailments, and high environmental risks especially hazardous living and working conditions, have been found to contribute to the ill health of the street children [5,6].

Other dimensions of social determinants of street child health have also been examined. Street children, particularly those living alone without families, are an integral part of the urban scenario and they lead harsh, precarious and hazardous lives. They have specific problems like deprivation of basic needs of health, nutrition, education, physical and sexual abuse, harassment and coercion by authority and by other people involved in anti-social activities. They don't have access to basic amenities like toilet facilities or a place to bathe. There is no place to keep their belongings and the money saved by them [7-9].

According to situational analysis of street children carried out in Mumbai, Bangalore, Kolkata, Delhi, Hyderabad, Indore and Chennai by the Ministry of Welfare, Government of India and UNICEF in 1988-89, health of most of the street children sampled in the studies was found to be in poor state. A test of the degree of nourishment show that $90 \%$ of the total of 2031 street children sampled in the city of Kolkata were undernourished while $3 \%$ of them were severely undernourished. Of these $65 \%$ of them have excessive lack of protein and essential vitamins. The data were based on the study of quantity and quality of food usually taken by the street children [9].

Although street children are more in need of health services than other children because of the "high-risk" environment, in which they constantly work and live, their access to health care is limited [10]. In Mumbai, it was observed that though $60 \%$ of the children had two meals a day, the nutritional value of the food was poor. As a result of under-nutrition, intake of nutritionally poor diet and unhygienic living conditions, children often suffered from diseases like: gastroenteritis, ringworm infections, anemia, vitamin A deficiency and rickets (Philips, 1992) [11].

Generally the street children suffer from seasonal ill- ness like cough, cold, fever and work related illnesses like scabies, backache and stomachache. Lack of hygiene in their lives increases the chances that wounds or infections picked up in the streets, where accidents and assaults are all too common, will become worse. It is difficult for street children to go to dispensaries partly because of lack of awareness about available medical facilities. Majority of them do not get any treatment. 9\% suffer from chronic illnesses, 16\% suffering from last 4 5 years. They usually get themselves treated at private clinics or medical stores in spite of being aware of the public health facilities; they use them very little $[12,13]$.

Homeless children are in poorer health than children who are not homeless. Lack of a good health care and the problems of growing up in unhygienic, hazardous and unprotected setting are primary factors that negatively affect the child's health [14].

One of the seven children born in India, says a study, suffer from breathing problems. In the unhygienic environment of the squatter settlements, where there is no regular process of garbage disposal or drainage of the waste water, children suffer a range of health disorders. Public health acre services are often the last choices of the families with sick children because of their distances, transportation difficulties, overcrowding, besides incurring a loss of daily wages [15]. These children are susceptible to various diseases due to their stay in unhygienic environments for most of the time.

The social dynamics of street child health are no different globally as reviewed by some researchers though the subject needs more exploration. Work conducted by Philadelphia Health Management Corporation (1985) and other research as well suggests that homeless children are also highly vulnerable to developmental delays and emotional disturbance. Developmental delays and emotional problems in homeless children may have their roots in the stresses of family life and homelessness and/or long-standing family problems [16].

Through the literature review and preliminary exploration of the area chosen for the study i.e., Sangam Vihar, an unauthorized colony of South Delhi, it was revealed that the problems of street children are wide. It was generally observed that a large majority of children are exposed to contaminated environmental elements. They do not have bathing and toilet facilities-public or private. Malnutrition and ill health are common amongst these children, and for many of them life is a hard, unending grind of poverty. In case of street children there is a general lack of any protection at work places or home, which in turn exposes them to negative forces.

Knowledge of the social dynamics of street children acting as root cause of their problems is a must for the formulation of policies and programmes. This necessitates an understanding of their social, cultural and eco- 
nomic life and it links with the political and administrative system of the city. However there were very few studies which examined this in detail.

Few social scientists have studied the problems of children, let alone the street children. Children lack any sort of power as compared to adults. Children are not involved in the decisions affecting their lives. But the Convention on Child Rights provides them with the right to have their opinions respected. The general response of the government to the speed and scale of global changes has been a reluctance to acknowledge the need for institutional change. This and several other micro level studies are required to make a beginning at understanding the conditions and forces that breed such children. The issue of neglect and abuse of such children in the slums and in the homes or in the factory or work units where they work has to be understood in its entirety.

This study [1] therefore also must be viewed as an attempt to define and understand the menace of child labour and street children in general. Further study has been done to look at the factors having an impact on the street child health in particular. The awareness and acceptability of the existing health programmes and services and their relevance to the needs of the street children has also been reviewed. The findings of this study serve to bring to light the dynamics of poverty and its implications for the street children. The understanding of the grass root situation provides reliable strategies, which could possibly assist in designing an appropriate plan of action. Analyzing their needs and aspirations, can possibly serve as a basis for development tasks, which will be specific, and need oriented; and be able to pay attention to the group as well as the individual. This in itself reiterates the need for understanding this and other such kind of studies.

Based on this need the research questions identified were the following:

\section{Research Questions}

- What socio-economic processes are likely to produce street children?

- What kind of families do they come from?

- What are the existing services and programmes for street children?

- What are their basic needs-economic, physical, psychological and social?

- How do these children deal with complexity in different domains of life; social, economic and political?

- Do the street children have low or no aspirations towards improving their quality of life?

\section{METHODOLOGY}

The study aimed to gather relevant information about the situation of the children in especially difficult circumstances in Sangam Vihar, one of the biggest unau- thorized colonies of South Delhi. The sample population comprised of street children in the age group of 5 - 16 years. The objectives of the study have been to analyse the physical, social and economic conditions in which the street children are living and their consequences for health of the street children in the age group of 5 - 16 years. It attempted to explore the degree of links with the family. The major focus of the study is the "child" as s/he experiences life and communicates. The situational analysis of the street children focused on the work opportunities that street children have in different sectors, the degree of their exploitation at the work place and otherwise. While work provides sustenance, it also breeds disillusionments regarding society and adults. The study explored their perceptions regarding these and their response to health related problems and health seeking behaviour. It created a profile of street children (family, work, street experiences, health status, aspirations, mutual bonds, control by adults, use of drugs and availability of health services) to facilitate a field level understanding of the social determinants having an impact on the health of street children.

In the absence of a consensus on any of the prevailing definitions of the street children, for this study, an operational definition of street children was used. The operational definition of street children used was:

Street Child is one who

- Is between 5 - 16 years of age;

- May or may not have family contacts;

- Spends most of the time on streets;

- Is usually working in unorganised sector and his work is low paid and hazardous;

- Is usually earning for his/family's livelihood;

- Is subjected to exploitation and ills of urbanization.

The study did not confine itself to one discipline but uses an interdisciplinary approach to present the social determinants of street child health. An exploratory cum descriptive research design has been used which is mostly qualitative. However the quantitative aspects were also not ignored. It is exploratory because it attempts to define the links between the socioeconomic situation of street children and its links to their health and perceptions about their life which are not known explicitly. Drawing upon the major concerns of the life of street children, whose needs are rarely understood, an in-depth interview schedule for the children was formulated. This was further supplemented by observations of the existing situation and case studies. The obtained data from 100 street children was coded in as many as ten categories under three domains, life of street children, health conditions of street children and role of the state and NGOs. From the coded data, frequencies and percentages were calculated on all the sections of the interview schedule. Many of the social and economic variables were ana- 
lysed qualitatively as well.

Limitations - the data was collected in a period of six months and the respondents comprised of children, both with and without families who spent most of their time on the streets. Limitations in data collection and enumeration were there but not enough to deter us from the purpose of the study. During the preliminary phase it was realised that there were more children in the age group of 9 - 16 years, spending their time on the streets and there were more boys as compared to girls. More number of children in the dominant age group was considered as the representative sample for the whole population. The children who were abandoned by the families or runaways were difficult to interview as they did not have any regular place to work or stay. More so, the children got distracted at the slightest pretext. Questions which had to be approximated were like age, hours of work based on the perception of 'time span' which was not familiar to the street children. The selection of a proper scientific sample was not possible because of the difficulties in enumerating the exact number of street and working children in the study area.

\section{FINDINGS}

This research work covered 100 street children in Sangam Vihar colony of South Delhi [1]. The socioeconomic and demographic profile of street children in the following section brings forth the actual social and economic determinants of the lives of street children.

- Socio-Economic and Demographic Profile of Street Children - the age-wise distribution of the total sample was carried out. The children were categorized in the three age groups, $5-8,9-12$ and $13-16$ years. Street children are strongly influenced by the age norms, the rules that define what is appropriate for them to do or to become at various ages. The largest number of street children (50\%) fell in the category of 13 - 16 years and the second largest number of children (41\%) was found in the category of $9-12$ years group. Street children in the age group of 5 - 8 years were found to be very less, comprising of $9 \%$ of the total sample. Few studies of street children so far conducted by Kuntay (1993); Reddy (1992); and D'Lima and Gosalia (1992), also found the largest number of street children in the age group of $11-15$ years.

- A look at the age composition of the street children reveals that they are in the formative years of their lives. These children on and off the streets, thus, fail to acquire mastery and competence to develop their personality adequately.

- Sex-Wise Distribution of the Sample - the sample of the street children comprised of $84 \%$ boys and $16 \%$ girls. The data does not support the fact that young girls are also becoming a part of the street life, however the numbers may rise as urban pressures of living on poor families continue to increase.

A more possible reason for finding fewer girls on the streets is that because girls are needed in the households, while boys are socialized into leaving homes much earlier, especially in our Indian society.

- Varieties of Street Children based on their Place of Living - the larger number of street children (74\%) was living with their families in small congested houses in the blocks of Sangam Vihar. These children work on the streets throughout the day and return to their homes in the late evening hours. $17 \%$ of children were living on the streets of the colony. These children live in small groups and belong to the category of "run-away" children. The other categories of street children were found in the market areas (5\%); near restaurants (3\%); and around bus stands (1\%) but had occasional contacts with their families. Almost one fourth of the total sample population did present the "run-away" and "living on their own" categories of street children. This group is essentially on the edge of 'high risk' category of street children.

- Migratory Characteristics of Street Children-many street children of Sangam Vihar colony owe their plight to the exodus from village to the big cities. Trapped in poverty, parents often neglect the children or even abandon them. These children venture on the streets. Most of the children (51\%) remembered having settled in Sangam Vihar as early as 10 or more years before and felt that belong to that area and Delhi.

- Reasons to Migrate to the City, as explained by the street children on repeated enquiry were to search for better employment opportunities (47\%); hope for prosperity (7\%) ; family problems in the village (2\%) and $6 \%$ considered desire for better facilities. $38 \%$ of street children did not specify any definite reason for migrating.

- Nature of the Family of Street Children-majority of the street children (76\%) reported that their fathers were either dead/absent and in case of $88 \%$ of the children, mother was alive. Father of most of these children was employed in semi-skilled jobs.

Findings revealed that almost $74 \%$ children in the study were either with their parents or their family members. The remaining $26 \%$ comprised of children who had distant family contacts and were living on their own. Most of these children were from families where if the father was employed his earnings were very less or was unemployed or absent. Thus the socio-economic status of the families of street children was poor. In other words the street children phenomenon seems to be mainly due to 
poverty stricken urban families.

- Size of the Family - most of the street children had nuclear families but the size of their families ranged between 2 - 11 members. This was mainly because of large number of siblings. $64 \%$ of children reported of having 4 - 5 siblings, the number which went to 6 - 9 siblings for 95 of the children. $49 \%$ of street children indicated having a family size of 6 - 8 members. 28\% children responded having 9 - 11 members in their families. Children born to the poor are a tangible asset.

The large size of nuclear families of these children in our study confirms the general belief that children in such families are considered economically useful, as a solution to poverty in many ways.

- Educational Status of Street Children-from the sample, only $15 \%$ were found to be attending school, as many as $85 \%$ were not studying. $40 \%$ of the children who were not attending any formal school education explained financial constraints and economic burden as the major reasons for not studying. Other $20 \%$ children indicated disinterest in schools; 19\% cited work pressure as the reason; $10 \%$, parental discouragement and household responsibilities as other reasons for not attending schools.

- Kind of Work of Street Children - the largest number of children were found to be working in the roadside restaurants selling quick street foods like tea, coffee, cold drinks, paan masala, cigarettes, etc. these were employed to work as assistants to the owner, helping in washing dishes, peeling and serving the vegetables and the food items. $17 \%$ of the street children were working in car garages as young mechanics in the making. Usually it was observed that a car garage has eight to ten children working in it to meet the demands of the client pressure. This is one of the only work situations where few children are working together, otherwise, street children are a loner group who move singularly in search of occupation. The third category of children (14\%) was occupied in the trade of rag picking and selling. These children are found practically in every part of the city, holding a huge plastic bag on the shoulders and often bare feet. Many girls were also involved in the trade of rag picking. $10 \%$ children were found selling vegetables around street corners; $5 \%$ worked as shoe polish boys; $3 \%$ sold magazines and newspapers on roadsides and; $9 \%$ of the street children were child beggars who moved swiftly within their areas and begged for little money.

- Choice of Work - the street children were all found to be engaged in the informal sector categorized by irregular working hours and no official documentation of the employees' wages. For the majority of children
(48\%) the availability of work became the choice of work. Only $8 \%$ children liked their work. Almost all the children $(80 \%)$ wanted to change their work, if appropriate opportunity came their way.

- The reasons children described for their work on the streets were: a) keeping busy and utilizing their time (35\%); b) no other alternative beside work (35\%); c) parental expectations to earn money (25\%); d) nonavailability of money in the family for education (5\%).

The fact that such a large proportion of street children are in some employment or the other, not because of their choice but because of the compulsions of the life, speaks volumes about their condition.

- Income of the Street Children-street children's income fell within the range of Rs 5 - 45/per day. 7\% of the children earned as less as Rs 5 - 10/per day. 21\% of the street children earned Rs 10 - 15/per day. 22\% of the children managed to earn Rs 15 - 20/per day and $17 \%$ earned Rs 20 - 25/per day. The income of the remaining $33 \%$ of the children rose steadily touching a high of Rs 45/per day. Looking at the work hours and the money earned by these children it is apparent that these children have to work beyond normal adult hours of working and are still deprived of basic necessities.

- Expenditure of the Earned Income by the Street Children - the analysis of the collected data revealed that the majority of the street children $(40 \%)$, spent the money either on themselves or gave it in the family. $36 \%$ of the children did not use the money on themselves at all, instead gave the whole money to the family for survival. Few children $17 \%$ spent the money mainly on themselves for small pleasures like movies or eating in life. This group mainly was of the run-away children who belong to their group on a mutual understanding of give and take and tend to show commitment to the peers.

\section{Case Study}

\section{Om Prakash}

Twelve years old Om Prakash definitely looked more like a seven to eight years old boy on the edge of middle childhood. He was frail and small structured but clever and sharp in the face. His parents live in Sangam Vihar but he has decided to live alone, on his own despite the availability of his parents and a home. He has found peer bondages and preferred to rather share his life and time with them, in place of living with the family.

Om Prakash feels attached to the mother. She usually earns meager amount of money by making chappaties' at the road side restaurants and at the weddings. Om Prakash revealed to the investigator that his parents have 
not shared a cordial and comfortable relationship for a long time. His father is a rickshaw puller who used to spend his daily earnings on drinking alcohol. He never supported the family economically, instead used to beat them after getting drunk every night. This situation has lead to tremendous family stress and daily discord. The father had recently married another woman and has broken all contacts with the family.

Om Prakash has a practice of roaming around the streets of Sangam Vihar, picking waste papers, glass, plastic, iron and other scrap materials. Like many other street children, to earn approximately Rs 30 - 40/per day. From this money, he buys himself food, bidies. While speaking he coughed continuously and started to smoke a bidi after the conversation was over.

He visits his mother once in a while. He lives with her for a day or two, gives her a little money and comes back to his street friends. In the late evenings he told with a smile that many of his friends collect on a concrete pavement outside a shop, where all the children laugh and play with each other. They play games with empty bottles, bottle lids and corks, explaining their own ways of gambling. Om Prakash goes to see Hindi films in a nearby theatre for which he spends any amount between Rs 35 - 50 depending on the availability of the type of ticket.

Om Prakash considers his pavement friends at his first family, who support him through difficult ties. "I will never go back permanently to my parents. I have no such desire." At a very young age Om Prakash has leant to be alone. He is illiterate and does not want to study. He is not healthy and has wounds all over the body. He could not undergo any treatment at the Government hospital, because the security guards of the Government hospital did not let him in, then has to take medicines from the private doctor of their colony, who though he thinks charges more but is quite nice in behaviour. Investigator observed that Om Prakash was having an open wound in his leg, which was infected. He informed that while collecting rag he got the cut on his foot with a broken glass. He has not been under any treatment. He says that the wound will heal by itself. When he goes for the rag picking in the colonies, some people give him old clothes and sometimes food also. He has no fixed place for sleeping. Sometimes he sleeps on the footpath also.

Mixed facts emerge as one analyses the different facets and pressures of the life of Om Prakash. He is sentimental and detached towards his relationships, honest in peer codes and unscrupulous with the strangers and both strong and vulnerable in dealing with the police. Physically not healthy suffering from cough and mild fever, yet considering himself strong and healthy-all at the same time.

\section{HEALTH CONDITIONS OF THE STREET CHILDREN}

- One important aspect of this study is to understand the health conditions of street children. In understanding the utilization of the health care delivery system and the health status of the street children it was important to assess their socio-economic situation as the social conditions in which they live often preclude them the right to have access to health services at par with the other sections of the society. Health as discussed earlier, embraces as many dimensions and medicine and medical care attend to only some aspects of health problems. The existing infrastructure of services in Sangam Vihar, supply of clean water, solid waster disposal system, acceptable housing was particularly deficient. The colony was unauthorized so it was not having cemented roads and health services by the government and authorized medical practitioners. There was no common sanitation and garbage disposal facility. In the absence of a public toilet in the colony, the children (both boys and girls) were compelled to relieve themselves in the open, becoming vulnerable to the sexual aggressiveness of some predatory adults. The basic provision of public sanitation would give them a measure of safety.

- Bathing Facilities - a large majority of street children, $59 \%$ reported having marginal space and facilities for bathing; almost another $41 \%$ of the children did not have any regular facilities for toilet, bathing and washing of clothes. Under such circumstances, children managed to bathe once or twice in a week at the closest water source available.

- Health Problems - the data revealed that most of the children suffered from fever very often followed by dysentery. Due to constant exposure to dirt, children were also suffering from cough and throat infection. The common illnesses they suffer from are, mainly skin diseases (38\%), fever (20\%), 12\% suffered from cold and $13 \%$ of them suffered from diarrhoea. $4 \%$ had wounds and $2 \%$ were suffering from TB and $11 \%$ had other ailments like headaches and body aches.

- In case of drinking water, women and children spend hours queuing up for it and collecting it and, in some cases, spend money to buy it.

- These children are more preoccupied with the bothering for daily earning than their health condition. This itself explains the attitude of street children in terms of availing medical treatment during the time of illness. 165 children often did not go in for treatment, $27 \%$ received home based remedies and $39 \%$ received from private quacks and $18 \%$, a small proportion availed services from Government hospitals.

To quote the experience of one of the street boys, $a 14$ 
years old, suffering from fever that he had to spend his full day's wages in getting the card made in AIIMS, a government hospital in Delhi and in commuting. However due to long queue everyday, he could not get an access to the doctor for the past three consecutive days. And in the process, he had spent all his meager savings as he could not work as well. Most of the street children therefore use private medical services, because they get the treatment though they have to pay more.

Analysis of health services revealed that they have been designed for the adults with rules and admission criteria, which excludes unaccompanied minors from receiving health services.

\section{MATTERS ARISING OUT OF FINDINGS}

This study explores in detail the social dynamics of street children in an urban setting of South Delhi. Besides the immediate concerns it raises some issues having policy and programme level dimensions like it showed difficulty in defining street children as they ranged from totally neglected to those living with families. It brought out the importance of not only their material but also emotional needs; the influence of adults they confront on road such as the employers, the area goons, the police and others. It found that there is no accurate assessment of the size of the problem since there is no consensus on any of the prevailing definitions for street children and the term street children is often used for child labour and vice versa. They are a floating population and are difficult to locate, leave alone count. This key proportion of at risk children is not tackled due to a rigid definition. This is a serious anomaly in definition and therefore coverage and it is in these places where NGOs like Butterflies, Prayas have reached but not the state welfare services.

The study also recognized the role of urbanization and migration in the creation of the street children. The findings revealed that in addition to the first generation migrants there was another set of families, which had lived in Delhi, long enough to be called the second generation of street families. Thus the children of these families entrapped in poverty are deprived of basic education and other facilities and are considered economically useful.

When the overall responses to the factors related to the community were analysed, it was realized that poor living conditions coupled with the lack of basic services such as water, toilet, electricity, exposes children to numerous health risks, stunting their growth potential.

Another major finding has been that the street children have no opportunity to have their employment regulated. Self employment is one way of surviving for many street children. The study suggested that the children are quite satisfied with the meager earnings from their frequently changing jobs but dissatisfied with their work. In the absence of purposeful saving they are just living for today. It was found in the study that the parents of these children sometimes have a very callous attitude for their children. The children also recognize this fact and understand the mercenary relations that they share with their parents. They blame their parents for the situation they are in and this shows that the parents who are the natural guardians do not always have the trust or ability to protect their children.

It was further realized that the street children had their own resourcefulness and creativity, serving as key factors of any strategy to improve their situation. Even among the run aways or lost children there was a remarkable sense of solidarity. Peer groups devise strategies to counter the menace of local thugs, bullying policemen and cushion each other in times of need. The study suggests that there is a sense of loss and loneliness in the crowded cities with nobody to care for them or recognize them enough to give them importance. They are suspected of criminal behaviour and face social exclusion. They face the evils of urbanization with no cushion or protection. They hardly enjoy any civic amenities and are most susceptible to be apprehended by police and institutionalized.

This piece of work showed the difficulty in defining children in need of care and protection ${ }^{2}$ clearly as they ranged from totally neglected to those living with families. It brought out the importance of not only their material but also emotional needs; the influence of adults they confront on road such as the employers, the area goons, the police and others. The issues for girl child were quite different and the most interesting finding was children's ability to create a collective amongst themselves, look after each other and have their small dreams.

These insights throw a range of questions such as

- Given the scarcity of resources can the Government policies and programmes actually provide for the increasing number of street children? Need of partnership with the local credible NGOs for a wider reach with a decentralized approach.

- Secondly the quality of health and education facilities provided.

- Last but not least the quality of life skills taught and their potential to help the children stand on their own.

\section{SUMMATION}

The findings of this study provide an insight of the lives of the street children which confirm that there cannot be any uni-approach towards improving the health situation of street children. The problem of street children is deep rooted and has multiple dimensions. Sug-

${ }^{2}$ The term "children in need of care and protection" has been used inter changeably with "street children" in this paper. 
gestions and recommendations for a better health condition of street children cannot be pinpointed to one cause, as it is a massive problem.

The existing services must converge and be extended to cover the most vulnerable target group of street children and new ones should be formulated to reach out to them. The street children have all rights to have an access to preventive and promotive health services. The problems of street children are of a special nature. Any plan of action must keep address the various determinants affecting their health and overall well-being.

The recommendations that follow should be seen as principles of action that need to be developed for, and applied in, specific national and local contexts.

- The Government must redefine its definition of the "street children" by including the children of slum dwellers staying with their families. They constitute the majority and are at high risk of becoming street children.

- There is an urgent need for capacity building of all the functionaries at Government, Non Government and local level in order to sensitize them about the various factors affecting the urban disadvantaged children and better reach them through a more childcentered approach.

- Political Capital-Political capital refers to having and using the right to participate in decision-making at all levels of society-neighbourhood, community, district and nation. Children who are so poor that scrambling for a subsistence livelihood is a daily struggle, are also likely to have little political capital. Children living in distrustful communities, where social ties are weak and networks are small or dysfunctional, and children who cannot read well enough to follow political debate, or have no access to mass media, are also likely to have little political capital.

It is important to consider children as potential partners in their own development. It was noted that the children can make valuable contributions to the situation analysis of the factors having impact on their daily life and overall well-being. Most children are their own best spokespersons, they are aware of the key problems of their neighborhood.

- Involving children especially disadvantaged children in situations where they can demonstrate competence can contribute to their self esteem.

- Situation Analyses as a means to an end: Findings generating from such research studies should be an integral part of the future programmes.

- The primary role of urban local bodies, decentralized towards community level is important in ensuring that services reach the urban poor children. Special and regular health campaigns for providing health care facilities to protect the street child and their families should be taken up by the Urban Basic Services, which need to be streamlined. It is also important to popularize the concept of night shelter. Protection to younger children is important in a night shelter.

The ground reality of the life of street children contrasts with the premises made on children's behalf by the distant governments. Their picture of poverty is of bleakness, tears, hunger and violence where their self generated resourcefulness keeps them going.

The findings argue, in essence, for a change in the role of the democratic state in relation to children especially those in difficult circumstances, without diminishing its responsibility to them; and seek a strategic departure from the beaten bureaucratic track, of alternating benevolence and indifference, towards steadily strengthening the natural capability of the family and the local community to care for children. The answer is not in the paternalistic attitude and institutionalization of these children, but is self help, participatory solutions that will foster self reliance, solutions that offer physical, emotional, social, cultural as well as the economic needs of these children and their communities.

\section{REFERENCES}

[1] Garg, A. (2002) An exploratory study of street children in Sangam Vihar. M.Phil Dissertation, Unpublished, Jawaharlal Nehru University, New Delhi.

[2] Qadeer, I. (1988) Health service system in India: An expression of socio-economic inequalities. The Great Concern, 1, 3-8.

[3] Banerji, D. (1981) Poverty, class and health culture in India, New Delhi, Prachi Prakashan. In: Shah, P., Ed., Child Labour, a Threat to Health and Development, Defence for Children International, Geneva.

[4] Nangia, P. (1987) Child labour, cause effect syndrome. Janak Publishers, New Delhi.

[5] Sondhi, P. (1989) Psychological profile of street children. Unpublished, Lady Irwin College, New Delhi.

[6] Reddy, N. (1992) Street children of Bangalore: A situational analysis. Child Labour Series, National Labour Institute, Noida.

[7] Ghosh, A. (1992) Street children of Calcutta. Child Labour Series, National Labour Institute, Noida.

[8] Pandey, R. (1993) Street children of Kanpur: A situational analysis. Child Labour Series, National Labour Institute, Noida.

[9] Bose, A.B. (1992) The disadvantaged urban child in India. Florence, UNICEF, International Child Development Centre, Italy.

[10] Arimpoor, J. (1992) Street children of Madras: A situational analysis. National Labour Institute, Noida.

[11] Philips, W. (1992) Street children of Indore. Child Labour Series, National Labour Institute, Noida. 
[12] Verma, S. and Dhingra, G. (1993) Who do they belong to? A profile of street children in Chandigarh. People's Action Journal, 8, 22-25.

[13] D'Lima and Gosalia, R. (1992) Street children of Bombay: A situational analysis. Child Labour Series, National Labour Institute, Noida.

[14] Mohan, S. (1990) Street children: An urban phenomenon. Social Welfare, $\mathbf{3}$.
[15] Aggarwal, K. (2002) Street Children the Cities of India. CANCL News Newsletter, 1, 2.

[16] Fox, E.R. and Roth, L. (1989) Children of homeless families: Health status and access to health care. The ANNALS of the American Academy of Political and Social Science, 506, 141-151. doi:10.1177/0002716289506001013 